\title{
Neonatal Neutrophils with Prolonged Survival Exhibit Enhanced Inflammatory and Cytotoxic Responsiveness
}

\author{
JOYCE M. KOENIG, JOSEPH J. STEGNER, ALISON C. SCHMECK, \\ MATTHEW A. SAXONHOUSE, AND LISA E. KENIGSBERG \\ University of Florida College of Medicine, Department of Pediatrics, Division of Neonatology, \\ Gainesville, Florida 32610
}

\section{ABSTRACT}

Stimulated cord blood PMN generated more ROI than did adult $\mathrm{PMN}$ at both $0 \mathrm{~h}$ and $24 \mathrm{~h}$; in addition, ROI levels in 24-h cord blood PMN were similar to those of 0-h adult PMN. We conclude that PMN with prolonged survival retain specific cytotoxic and inflammatory functions, and these are enhanced in cord blood PMN. We speculate that neonatal PMN with prolonged survival have the functional capacity to contribute to the pathogenesis of inflammatory disorders. (Pediatr Res 57: 424-429, 2005)

$\quad$ Abbreviations
CLD, chronic lung disease
DHR, dihydrorhodamine 123
fMLP, formyl-methionine-leucine-phenylalanine
PE, phycoerythrin
PMA, phorbol 12-myristate 13-acetate
PMN, neutrophil(s)
ROI, reactive oxygen intermediates
7-AAD, 7-aminoactinomycin

PMN serve as the primary line of host defense during the early stages of sepsis and inflammation (1). After activation by systemic or local factors, primed endothelial cells interact with PMN through adhesion molecules that include selectins and integrins (2). These adhesive interactions initiate a process that allows the extravasation of PMN into inflamed tissue with the goal of neutralizing the inciting stimulus. In the case of in-

Received May 20, 2004; accepted August 18, 2004.

Correspondence: Joyce M. Koenig, M.D., Department of Pediatrics, Division of Neonatology, PO Box 100296, University of Florida, Gainesville, FL 32610-0296; e-mail: koenijm@peds.ufl.edu

Supported, in part, by grants from the National Institutes of Health (HD41559) and Clinical Research Center Grant RR00082, both to J.M.K.; from Children's Miracle Network (J.M.K.), and from the American Cancer Society (R.G. Thompson Memorial Summer Student Research Fellowship, A.C.S.).

This research was presented, in part, to the Society for Pediatric Research, San Francisco, CA, 2004.

DOI: 10.1203/01.PDR.0000153945.49022.96 flammation mediated by bacterial or fungal microorganisms, phagocytosis and subsequent killing of these invaders occurs through mechanisms that partly involve ROI and proteases $(3,4)$.

The concept that apoptosis of inflammatory PMN and their timely removal by resident macrophages are critical to the resolution of inflammation has been well established $(5,6)$. During the resolution phase, PMN typically undergo the phenotypic changes associated with apoptosis, which promotes their removal by resident macrophages (7). PMN can also undergo necrosis and lysis, a process that induces cytotoxicity in surrounding tissues (8), although apoptosis is the more common and physiologically preferable route. All cells are programmed for senescence, and this program is especially prominent in PMN, cells with foreshortened half-lives. Apoptosis of PMN involves surface changes in the plasma membrane, including expression of phosphatidylserine residues and 
receptors that facilitate their phagocytosis by macrophages (6). The integrity of the cell membrane is preserved in apoptotic PMN, which potentially confers protection to the local environment from cytoplasmic proteases and enzymes. Furthermore, apoptotic PMN in adults have decreased functional capacity, which further contributes to the down-regulation of PMN stimulation during the resolution of inflammation $(2,9)$.

The delayed removal of activated PMN appears to be a critical component in the pathogenesis of a variety of chronic inflammatory and autoimmune disorders in adults (10-13), although less is known about PMN apoptosis in the pediatric population. Infants who are delivered very early in gestation are at risk for developing the inflammatory lung disorder, bronchopulmonary dysplasia. The etiology of this CLD of premature infants is unclear and has been associated with a myriad of risk factors $(14,15)$. Persistence of lung PMN is one characteristic associated with CLD; however, whether a delay in the apoptosis of these PMN contributes to their persistence, as has been suggested, has not been established $(16,17)$.

We previously determined that neonatal PMN have a delay in their onset of spontaneous and Fas-mediated apoptosis in vitro (18). PMN that survive conditions associated with spontaneous apoptosis retain some degree of functionality (9), although whether this applies to neonatal PMN has not been described. We reasoned that retained functional capacity in surviving neonatal PMN might not only delay their clearance by the reticuloendothelial system, but could augment the inflammatory response by promoting PMN-endothelial interactions as well as the incitement of injury to surrounding tissues. In this article, we present the results of studies designed to test our hypothesis that surviving, nonapoptotic neonatal PMN retain their inflammatory and cytotoxic potential.

\section{METHODS}

PMN isolation and culture. Samples from the umbilical veins of term placentas after uncomplicated cesarean section or from the peripheral venous blood of healthy adult volunteers were collected into heparinized syringes and processed immediately. Samples were obtained following informed consent in accordance with the guidelines of the Institutional Review Board for Human Studies at the University of Florida.

Dextran-sedimented leukocytes were subjected to density centrifugation, and the resultant was subjected to hypotonic lysis of contaminating erythrocytes, as previously described (19). Isolated PMN (10 ${ }^{6}$ cells $\left./ \mathrm{mL}\right)$ suspended in RPMI 1640/2\% FCS (Mediatech Inc., Herndon, VA) were cultured in polypropylene tubes at $37^{\circ} \mathrm{C}, 5 \% \mathrm{CO}_{2}$, for up to $24 \mathrm{~h}$.

Up-regulation of surface CD11b on PMN after chemotactic stimulation. After culture, PMN aliquots were washed with $\mathrm{Ca}$ - and $\mathrm{Mg}$-free PBS, then incubated with either PBS alone (control) or in the presence of $10 \mathrm{nM}$ fMLP (Sigma Chemical Co., St. Louis, MO) for $15 \mathrm{~min}$ at $37^{\circ} \mathrm{C}$. Cells were then washed in PBS and stained with an anti-CD11b MAb conjugated to PE ( $\operatorname{IgG}_{2 \mathrm{a}}$, clone D12) or a PE-conjugated isotype control $\mathrm{IgG} \mathrm{Ab}$ (both from BD Immunocytometry Systems, San Jose, CA), then washed with PBS. To differentiate between nonapoptotic, early apoptotic, and late apoptotic/necrotic populations, PMN stained with anti-CD11b MAb, or its isotype control, were subsequently treated with annexin $\mathrm{V}$, which binds exposed phosphatidylserine residues on apoptotic cells (20), and 7-AAD, a stain that identifies nonviable, necrotic cells in combination with annexin V $(21,22)$. Briefly, $10^{6} \mathrm{PMN}$ were suspended in $1 \mathrm{~mL}$ binding buffer (BD PharMingen, San Diego, CA) and 100 $\mu \mathrm{L}$ aliquots were removed for staining with $5 \mu \mathrm{L}$ of annexin V-FITC (BD PharMingen) and $15 \mu \mathrm{L}$ of $100 \mu \mathrm{g} / \mathrm{mL}$ 7-AAD (Sigma Chemical Co.). Cells were incubated for $15 \mathrm{~min}$ in the dark at room temperature (RT), followed by the addition of $400 \mu \mathrm{L}$ of $1 \times$ binding buffer. Compensation of FITC and PE was performed using CaliBRITE beads (BD Immunocytometry). Using multicolor flow cytometric analysis (BD FACScan; BD Biosciences, Lexington, $\mathrm{KY}$ ), surface expression of CD11b on unstimulated and fMLP-stimulated
PMN, in both the apoptotic/non-necrotic and nonapoptotic populations, was determined by measuring the mean fluorescence of at least 5000 gated events in the FL1-FL2 channels, after exclusion of the 7-AAD-positive (late apoptosis/necrotic) populations. PMN populations were identified and gated based on specific forward- and side-scatter characteristics.

Enrichment of the nonapoptotic PMN fraction. Nonapoptotic PMN were separated from apoptotic PMN in 24-h cultures using immunomagnetic techniques, which we modified for this study $(9,23)$. Briefly, cell aliquots were removed from culture and combined to obtain approximately $20-25 \times 10^{6}$ PMN. After a PBS wash, PMN were suspended in $0.1 \mathrm{~mL}$ binding buffer, then stained with $20 \mu \mathrm{L}$ annexin V-PE (both from BD PharMingen) for $15 \mathrm{~min}$ at RT. PMN washed in binding buffer were then resuspended in $1 \mathrm{~mL}$ of the buffer. The cell suspension was stained with $100 \mu \mathrm{L}$ of an anti-PE selection cocktail for $15 \mathrm{~min}$ at RT, followed by an incubation with $50 \mu \mathrm{L}$ of magnetic nanoparticles (EasySep, StemCell Technologies, Vancouver, BC, Canada) for $10 \mathrm{~min}$ at RT. After the addition of $1.5 \mathrm{~mL}$ binding buffer, the PMN-magnetic particle suspension was transferred to a polystyrene tube, which was then placed in a magnet (EasySep), as per the manufacturer's instructions. The purity of the nonapoptotic (annexin V-negative) PMN suspensions was $>90 \%$ as determined by flow cytometric analysis of eluted PMN by annexin V-PE staining. The resultant annexin V-negative enriched PMN were then incubated with PMA or PBS and stained using the DHR assay, as described below.

Measurement of ROI elaboration. This group of studies was designed to measure PMN elaboration of ROI, one marker of cytotoxic function. We used the flow cytometric DHR assay to determine ROI elaboration in 0-h PMN and in 24-h PMN enriched for the nonapoptotic fraction (as outlined above). The DHR assay is based on the oxidation of nonfluorescent DHR to the greenfluorescent compound, rhodamine 123, in the presence of ROI, particularly superoxide anion and hydrogen peroxide $(24,25)$. Briefly, PMN at $0 \mathrm{~h}$ and $24 \mathrm{~h}$ (enriched annexin $\mathrm{V}$-negative populations) were washed in PBS and resuspended in $0.2 \mathrm{~mL}$ PBS $\left(5 \times 10^{6}\right.$ cells $\left./ \mathrm{mL}\right)$. Cells were incubated either in the presence of $10 \mathrm{nM}$ PMA (Sigma Chemical Co.) to stimulate ROI production, or in PBS alone, for $15 \mathrm{~min}$ at $37^{\circ} \mathrm{C}$. The reaction was stopped by washing treated PMN with ice-cold PBS. PMN in $0.2 \mathrm{~mL} \mathrm{PBS}$ were stained with $10 \mu \mathrm{L}$ DHR (Sigma Chemical Co., $500 \mathrm{ng} / \mathrm{mL}$ final) and incubated for $10 \mathrm{~min}$ at $37^{\circ} \mathrm{C}$. After incubation, $500 \mu \mathrm{L}$ ice-cold PBS were added to the stained cells, which were then kept on ice. The degree of rhodamine fluorescence emitted by stained PMN was immediately analyzed by flow cytometry on at least 5000 gated events, using the FL1 channel.

Data analysis. Data were analyzed by $t$ test or one-tailed ANOVA, as appropriate, using SigmaStat for Windows software (Version 2.03, SPSS, Inc., Chicago, IL). A $p$ value $<0.05$ was considered to be statistically significant. Data are presented as the mean $\pm \mathrm{SD}$.

\section{RESULTS}

Functional CD11b expression is maintained on PMN with prolonged survival. At $0 \mathrm{~h}$, the majority (>96\%) of PMN in cultures derived from adults or umbilical cord blood were nonapoptotic, as determined by negativity for annexin $\mathrm{V}$ staining (Fig. 1); the proportion of necrotic PMN was $<1 \%$ in either population. A greater proportion of cord blood PMN were nonapoptotic (annexin V-negative) after $24 \mathrm{~h}$ of culture (35 \pm $3 \%)$ compared with adult PMN $(14 \pm 4 \%, p<0.001)$, similar to differences we previously reported (18). At $24 \mathrm{~h}$, the proportion of necrotic (annexin V-positive/7-AAD-positive) PMN were similar in cord blood $(6 \pm 5 \%)$ and adult $(7 \pm 2 \%$, $p=0.35$ ) cultures.

We observed that surface levels of CD11b were higher on cord blood PMN at $0 \mathrm{~h}$ in the baseline, unstimulated state (mean fluorescence, $718 \pm 12)$ than in adult PMN (594 \pm 82 , $p<0.05$ ) (Fig. 2, $A$ and $B$ ). However, chemotactic stimulation with fMLP increased surface expression of CD11b to a greater degree in adult PMN than in cord blood PMN (Fig. 3), results that are similar to those we and others have observed $(19,26,27)$.

In 24-h surviving, nonapoptotic (annexin V-negative) cord blood and adult PMN (Fig. 2, $A$ and $B$ ), baseline surface levels of $\mathrm{CD} 11 \mathrm{~b}$ were lower than those measured at baseline at $0 \mathrm{~h}$ 


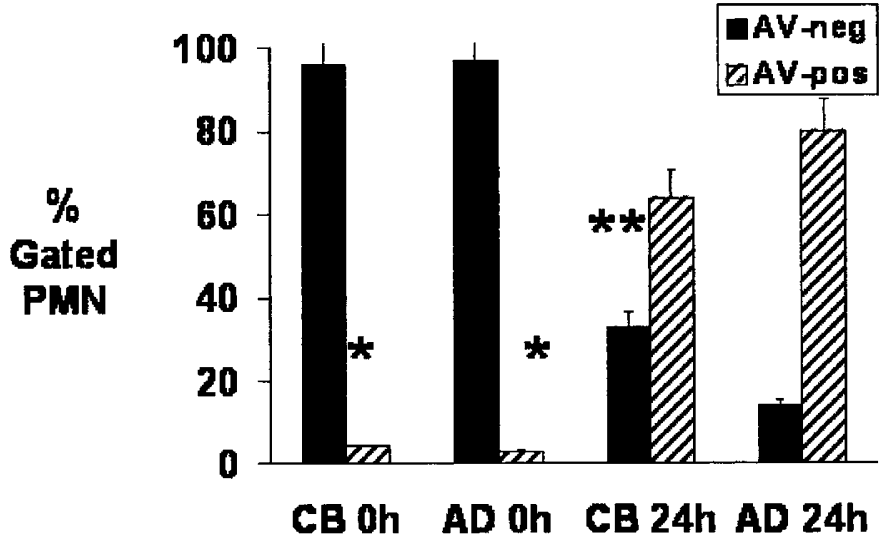

Figure 1. Surviving and apoptotic cord blood and adult PMN at $0 \mathrm{~h}$ and $24 \mathrm{~h}$. To differentiate between surviving, nonapoptotic PMN, viable apoptotic PMN, and necrotic, nonviable PMN, cord blood $(C B)$ and adult $(A D)$ cells at $0 \mathrm{~h}$ and after $24 \mathrm{~h}$ of culture were stained with annexin V-FITC and 7-AAD, and gated PMN populations were analyzed by multicolor flow cytometry. The annexin V-negative (AV-neg) populations represent viable, nonapoptotic PMN; the annexin $\mathrm{V}$-positive (AV-pos) populations represent the apoptotic, non-necrotic PMN (AV-pos/7-AAD-neg) population. Results represent data from experiments performed in duplicate $(n=5)$. $* p<0.001,0$-h AV-neg PMN (CB, AD) vs 24-h AV-neg PMN (CB, AD). ** $p<0.001$, CB 24-h AV-neg PMN vs AD 24-h AV-neg PMN.

(cord blood PMN: $189 \pm 66$ versus $749 \pm 267, p<0.001$; adult PMN: $269 \pm 38$ versus $594 \pm 82, p<0.001$ ), and baseline surface expression of CD11b was higher on nonapoptotic adult PMN than on nonapoptotic cord blood PMN $(p<$ 0.05). Stimulation with fMLP of surviving, nonapoptotic cord blood PMN induced a greater degree of up-regulation of surface CD11b levels from baseline values $(202 \pm 110 \%)$ than the degree of stimulation observed in 0-h cord blood PMN (63 $\pm 34 \%, p<0.05$; Fig. 3). In contrast, in adult samples, stimulation with fMLP induced up-regulation of CD11b to a similar degree at $0 \mathrm{~h}$ and in surviving 24-h PMN (164 $\pm 57 \%$ versus $166 \pm 62 \%)$. Stimulation of nonapoptotic PMN with fMLP induced the up-regulation of surface CD11b to levels that were $46 \%$ and $51 \%$ of levels on stimulated 0 -h cord blood and adult PMN, respectively. Surface CD11b levels on stimulated nonapoptotic cord blood $(517 \pm 13)$ and adult $(731 \pm$ 258) PMN were not statistically different from each other $(p=$ $0.24)$.

Baseline surface expression of CD11b on the 24-h apoptotic, annexin $\mathrm{V}$-positive populations was not different between adult $(249 \pm 57)$ and cord blood PMN $(188 \pm 91, p=0.22$; Fig. 2). Unlike the responses of nonapoptotic PMN, surface expression of $\mathrm{CD} 11 \mathrm{~b}$ on annexin $\mathrm{V}$-positive, apoptotic cord blood or adult PMN did not increase over their respective baseline levels following stimulation with fMLP (Fig. 2, $A$ and $B$; Fig. 3).

PMN with prolonged survival generate ROI. Using the DHR assay and flow cytometric analyses, we examined the elaboration of ROI at baseline and after PMA stimulation in 0 -h adult and cord blood PMN, and at $24 \mathrm{~h}$ in PMN cultures enriched for the annexin $\mathrm{V}$-negative fraction. At $0 \mathrm{~h}$, PMN from both adult and cord blood sources showed minimal elaboration of ROI under baseline conditions (Fig. 4). In contrast, stimulation of these PMN with the phorbol ester PMA
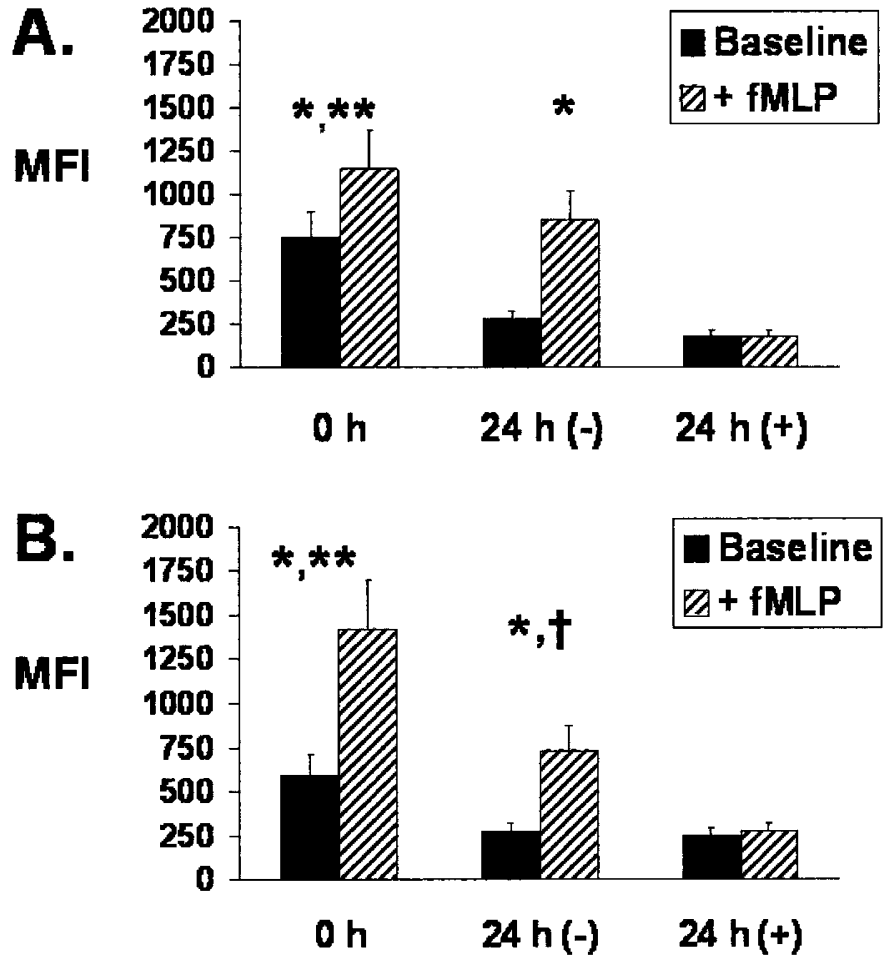

Figure 2. Surface CD11b expression on $0 \mathrm{~h}$ and $24 \mathrm{~h} \mathrm{PMN}$ after chemotactic stimulation. At 0 and $24 \mathrm{~h}, \mathrm{CB}(A)$ and $\mathrm{AD}(B)$ PMN were incubated with PBS alone (baseline) or fMLP $(10 \mathrm{nM})$ for $15 \mathrm{~min}$. After washing, cells were stained with annexin V-FITC, CD11b-PE, and 7-AAD. Gated PMN populations were analyzed by multicolor flow cytometry. Shown is the mean fluorescence intensity $(M F I)$ of surface PMN CD11b at baseline or after chemotactic stimulation (+fMLP) at $0 \mathrm{~h}$, at $24 \mathrm{~h}$ in nonapoptotic annexin $\mathrm{V}$-negative PMN [24 h(-)], and at $24 \mathrm{~h}$ in annexin $\mathrm{V}$-positive (apoptotic/non-necrotic) [24 $\mathrm{h}(+)]$ PMN. Results represent data from experiments performed in duplicate $(n=8) . * p<0.001$, baseline $v s$ stimulated CD11b levels; $* * p<0.05$, baseline CD11b on $0 \mathrm{~h}$ PMN vs baseline CD11b levels on $24 \mathrm{~h}(-)$ PMN and $24 \mathrm{~h}(+) \mathrm{PMN} ; \dagger p<0.05$, stimulated CD11b levels on $24 \mathrm{~h}(-)$ PMN vs stimulated $\mathrm{CD} 1 \mathrm{~b}$ levels on $0 \mathrm{~h}$ and $24 \mathrm{~h}(+)$ PMN.

induced generation of ROI in both cell populations, with a greater relative expression of ROI in cord blood PMN samples (mean fluorescence, $876 \pm 320$ versus $600 \pm 139$ in adult PMN; $p<0.05)$. In studies of 24-h nonapoptotic PMN, PMA-stimulated cord blood PMN samples also had greater expression of ROI $(458 \pm 224)$ than did stimulated nonapoptotic adult PMN $(280 \pm 105, p<0.05)$. In addition, although the expression of ROI was lower on 24-h nonapoptotic PMN compared with 0-h PMN, ROI expression on 24-h nonapoptotic cord blood PMN was not different from ROI expression on freshly isolated 0 -h adult PMN $(p=0.22)$.

\section{DISCUSSION}

Our goal in the present study was to determine whether surviving neonatal PMN retain their potential for inflammatory and cytotoxic activity. In a set of in vitro experiments, we determined that, compared with adult PMN, nonapoptotic cord blood PMN that survived $24 \mathrm{~h}$ of culture had an enhanced response to stimulation as evidenced by their capacity to up-regulate CD11b and to elaborate ROI.

In studies focusing on inflammatory function, we observed that cord blood and adult PMN had a lower surface expression 


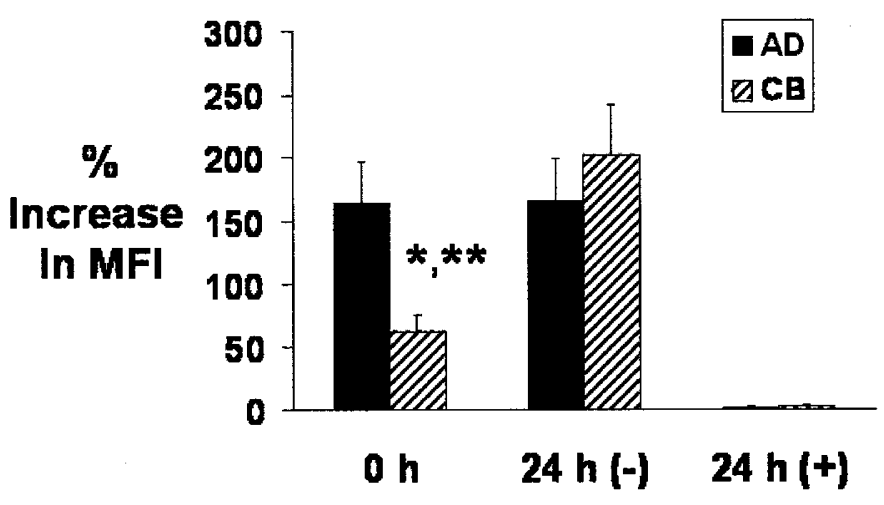

Figure 3. Up-regulation of $\mathrm{CD} 11 \mathrm{~b}$ on $0 \mathrm{~h}$ and $24 \mathrm{~h} \mathrm{PMN}$ after chemotactic stimulation. Shown is the percentage up-regulation (increase) of surface CD11b levels (mean fluorescence intensity, MFI) after stimulation with fMLP $(10 \mathrm{nM})$ in $0 \mathrm{~h}$ PMN, in surviving, nonapoptotic PMN [24 $\mathrm{h}(-)]$, and in apoptotic PMN $[24 \mathrm{~h}(+)]$ from cord blood $(C B)$ and from adults $(A D)$. Results represent data from experiments performed in duplicate $(n=8) .{ }^{*} p<0.05$, percentage up-regulation of CD11b on $0 \mathrm{~h} \mathrm{CB} \mathrm{PMN} \mathrm{vs} 0 \mathrm{~h} \mathrm{AD} \mathrm{PMN;} \mathrm{**p}<$ 0.05, percentage up-regulation of CD11b on $0 \mathrm{~h} \mathrm{CB}$ PMN vs $24 \mathrm{~h}(-) \mathrm{CB}$ PMN.

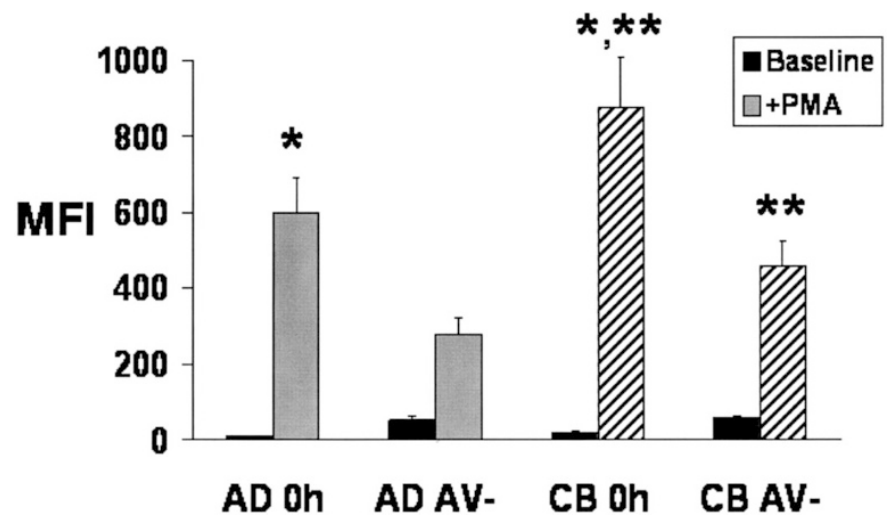

Figure 4. PMA-stimulated elaboration of ROI on surviving and apoptotic PMN. 0 h PMN and nonapoptotic, annexin V-negative (AV-) PMN from adult $(A D)$ and cord blood $(C B)$ were incubated with PBS alone (baseline) or with PMA $(10 \mathrm{nM})$. After incubation, cells were stained with DHR and gated PMN populations were analyzed by flow cytometry in the FL1 channel. Shown here is the mean fluorescence intensity $(M F I)$ of $0 \mathrm{~h}$ PMN and surviving (AV - ) 24-h PMN at baseline or after PMA stimulation. Results represent data from experiments performed in duplicate $(n=9)$. $* p<0.001$, PMAstimulated ROI levels in 0-h PMN vs 24-h AV- PMN; ** $p<0.05$, PMAstimulated ROI levels in CB PMN (0 h, $24 \mathrm{~h} \mathrm{AV-)}$ vs AD PMN (0 h, $24 \mathrm{~h}$ AV-).

of CD11b after $24 \mathrm{~h}$ of culture compared with 0-h levels. Surviving 24-h adult PMN retained their capacity to upregulate $\mathrm{CD} 11 \mathrm{~b}$ in response to chemotactic stimulation, confirming observations made by Dransfield et al. (9). In contrast, although 0-h cord blood PMN had impaired up-regulation of $\mathrm{CD} 11 \mathrm{~b}$, as previously reported (28), stimulated surviving 24-h cord blood and adult PMN increased surface CD11b levels to a similar degree. The preservation of this function in surviving PMN has implications for their inflammatory potential. Upregulation of surface $\mathrm{CD} 11 \mathrm{~b}$ in response to stimulation is critical to PMN-endothelial adhesion and is an important initial step during inflammation (29). This adherence is partly mediated through the interactions of PMN $\beta 2$ integrins, including CD11b, with endothelial ligands such as ICAM-1, the expres- sion of which are increased on activated endothelium. Studies have shown a preponderance of ICAM-1 on lung vascular surfaces and in soluble form in the lung effluent and in the sera of premature neonates at risk for developing CLD (30). Pertinently, adult PMN with prolonged survival retain their capacity to adhere to fibrinogen, a CD11b-mediated event (9). Our observations of similar CD11b expression on surviving adult and cord blood PMN suggests that surviving cord blood PMN also retain an adhesive capacity, although this remains to be tested. Such functional interactions of surviving neonatal PMN with vascular endothelium would likely contribute to the persistence of the inflammatory response.

Neonatal PMN have a variety of functional impairments (26, $27,31,32$ ) that might be related to incomplete terminal differentiation, as suggested by observations that segmented PMN in the bone marrow are functionally immature compared with those in the circulation (33). Cord blood has been observed to contain a mixed population of immature and mature PMN, and lower expression of CD11b was associated with decreased PMN maturity (34). Thus, the subset of cord blood PMN resistant to apoptosis might represent a population that attains an "adult phenotype" under conditions that promote apoptosis in more mature PMN. Our observation of the enhanced upregulation of $\mathrm{CD} 11 \mathrm{~b}$ on stimulated 24-h cord blood PMN to the degree achieved by adult PMN lends support to this possibility.

To begin to define the cytotoxic potential of surviving neonatal PMN, we designed studies to determine their elaboration of ROI. We determined that 0 -h cord blood PMN had a greater elaboration of ROI in response to phorbol ester stimulation compared with adult PMN, an observation also made by other investigators $(32,35,36)$. After $24 \mathrm{~h}$ of culture, ROI elaboration was proportionately decreased in nonapoptotic PMN from both groups. However, nonapoptotic cord blood PMN maintained an enhanced responsiveness to stimulation relative to that of adult PMN, and, in fact, elaborated ROI at levels similar to those of $0 \mathrm{~h}$ adult PMN, an observation that also promotes the notion of an ongoing functional maturation of cord blood PMN. The elaboration of ROI by PMN is an important and necessary element in the elimination of pathogens during the clearance of infection (37) and is thus a beneficial aspect of normal PMN function. Conversely, the continued elaboration of ROI by lung PMN in the absence of a requirement for bactericidal activity has implications for damaging effects to the lung parenchyma $(38-41)$. The significant degree of ROI elaboration by surviving neonatal PMN that we observed suggests that these cells are potent inducers of tissue injury.

PMN have been implicated as critical perpetrators of chronic inflammation in a variety of disorders, including CLD, and is a topic that has been elegantly reviewed (6). The persistence of lung PMN is a well-accepted characteristic of inflammatory lung diseases in both adults and neonates $(38,42,43)$. Longstanding observations have confirmed a contributory role of oxygen radicals to the etiology of chronic lung inflammation in both the adult and neonatal populations $(6,38-40)$. Furthermore, oxygen radicals have been shown to mediate DNA damage (44), an important mechanism of lung injury $(45,46)$. PMN are not the sole source of ROI; other leukocytes, as well as the lung microenvironment itself, can potentially elaborate 
these mediators $(38,47)$. However, PMN are a major source of oxygen radicals $(48,49)$, and evidence has shown a link between the depletion of PMN and a diminished development of inflammation in a variety of animal models $(42,50,51)$.

Several recent studies have shown delayed apoptosis of lung PMN in premature neonates at risk for developing CLD $(16,17)$, although the involved mechanisms remain to be defined. In previous in vitro studies, we observed that neonatal PMN had an intrinsic delay in both spontaneous and Fasmediated apoptosis (18), which was associated with decreased activity of caspase-3 (52), a critical downstream mediator of PMN apoptosis (53). Delayed apoptosis and the subsequent survival of PMN leads to their persistence in tissues, because PMN removal by the reticuloendothelial system depends on the recognition of, and ingestion of, apoptotic PMN by resident macrophages (5-7). Our present studies confirm previous observations of preserved function in adult PMN with prolonged survival $(9,54)$. In addition, however, we provide evidence that surviving cord blood PMN have an enhanced responsiveness to inflammatory stimuli. The intrinsic survival tendency of these PMN, combined with their functional robustness, indicate their potential contribution to the pathogenesis of neonatal inflammation. Certainly, other inflammatory cells, such as alveolar macrophages, or the cellular components of the microenvironment itself, likely play an important contributory role as well. Studies are currently underway to further define the functional capacity of surviving PMN and to investigate their role in these complex cellular interactions. In addition, a more complete understanding of the age-related factors that regulate PMN apoptosis and survival may be important in developing novel therapeutic approaches to neonatal inflammation $(41,55)$.

Acknowledgments. The authors thank Pam Connolly, R.N., and Ann Cothran, R.N., the General Clinical Research Center at the University of Florida, and the labor and delivery staff at Shands Hospital at the University of Florida for helping us obtain umbilical cord blood specimens.

\section{REFERENCES}

1. Hotchkiss RS, Karl IE 2003 The pathophysiology and treatment of sepsis. N Engl J Med 348:138-150

2. Seely AJ, Pascual JL, Christou NV 2003 Science review: cell membrane expression (connectivity) regulates neutrophil delivery, function and clearance. Crit Care 7:291307

3. Baehner RL 1975 Microbe ingestion and killing by neutrophils: normal mechanisms and abnormalities. Clin Haematol 4:609-633

4. Nagl M, Kacani L, Mullauer B, Lemberger EM, Stoiber H, Sprinzl GM, Schennach H, Dierich MP 2002 Phagocytosis and killing of bacteria by professional phagocytes and dendritic cells. Clin Diagn Lab Immunol 9:1165-1168

5. Haslett C 1999 Granulocyte apoptosis and its role in the resolution and control of lung inflammation. Am J Respir Crit Care Med 160:S5-S11

6. Matute-Bello, G Martin TR 2003 Science review: apoptosis in acute lung injury. Crit Care 7:355-358

7. Savill JS, Wyllie AH, Henson JE, Walport MJ, Henson PM, Haslett C 1989 Macrophage phagocytosis of aging neutrophils in inflammation. Programmed cell death in the neutrophil leads to its recognition by macrophages. J Clin Invest 83:865-875

8. Haslett C 1992 Resolution of acute inflammation and the role of apoptosis in the tissue fate of granulocytes. Clin Sci (Lond) 83:639-648

9. Dransfield I, Stocks SC, Haslett C 1995 Regulation of cell adhesion molecule expression and function associated with neutrophil apoptosis. Blood 85:3264-3273

10. Savill J, Dransfield I, Gregory C, Haslett C 2002 A blast from the past: clearance of apoptotic cells regulates immune responses. Nat Rev Immunol 2:965-975

11. Tsujimoto H, Takeshita S, Nakatani K, Kawamura Y, Tokutomi T, Sekine I 2001 Delayed apoptosis of circulating neutrophils in Kawasaki disease. Clin Exp Immunol 126:355-364
12. Starkebaum G 2002 Chronic neutropenia associated with autoimmune disease. Semin Hematol 39:121-127

13. Najarian DJ, Gottlieb AB 2003 Connections between psoriasis and Crohn's disease J Am Acad Dermatol 48:805-821

14. Ikegami M, Jobe AH 2002 Postnatal lung inflammation increased by ventilation of preterm lambs exposed antenatally to Escherichia coli endotoxin. Pediatr Res $52: 356-362$

15. Weinberger B, Laskin DL, Heck DE, Laskin JD 2002 Oxygen toxicity in premature infants. Toxicol Appl Pharmacol 181:60-67

16. Kotecha S, Mildner RJ, Prince LR, Vyas JR, Currie AE, Lawson RA, Whyte MK 2003 The role of neutrophil apoptosis in the resolution of acute lung injury in newborn infants. Thorax 58:961-967

17. Oei J, Lui K, Wang H, Henry R 2003 Decreased neutrophil apoptosis in tracheal fluids of preterm infants at risk of chronic lung disease. Arch Dis Child Fetal Neonatal Ed 88:F245-F249

18. Allgaier B, Shi M, Luo D, Koenig JM 1998 Spontaneous and Fas-mediated apoptosis are diminished in umbilical cord blood neutrophils compared with adult neutrophils. J Leukoc Biol 64:331-336

19. Koenig JM, Simon J, Anderson DC, Smith E, Smith CW 1996 Diminished soluble and total cellular L-selectin in cord blood is associated with its impaired shedding from activated neutrophils. Pediatr Res 39:616-621

20. Vermes I, Haanen C, Steffens-Nakken H, Reutelingsperger C 1995 A novel assay for apoptosis. Flow cytometric detection of phosphatidylserine expression on early apoptotic cells using fluorescein labelled Annexin V. J Immunol Methods 184:39-51

21. Derby E, Reddy V, Kopp W, Nelson E, Baseler M, Sayers T, Malyguine A 2001 Three-color flow cytometric assay for the study of the mechanisms of cell-mediated cytotoxicity. Immunol Lett 78:35-39

22. Lecoeur H, de Oliveira-Pinto LM, Gougeon ML 2002 Multiparametric flow cytometric analysis of biochemical and functional events associated with apoptosis and oncosis using the 7-aminoactinomycin D assay. J Immunol Methods 265:81-96

23. Sandstrom K, Hakansson L, Lukinius A, Venge P 2000 A method to study apoptosis in eosinophils by flow cytometry. J Immunol Methods 240:55-68

24. Emmendorffer A, Hecht M, Lohmann-Matthes ML, Roesler J 1990 A fast and easy method to determine the production of reactive oxygen intermediates by human and murine phagocytes using dihydrorhodamine 123. J Immunol Methods 131:269-275

25. Vowells SJ, Sekhsaria S, Malech HL, Shalit M, Fleisher TA 1995 Flow cytometric analysis of the granulocyte respiratory burst: a comparison study of fluorescent probes. J Immunol Methods 178:89-97

26. Anderson DC, Abbassi O, Kishimoto TK, Koenig JM, McIntire LV, Smith CW 1991 Diminished lectin-, epidermal growth factor-, complement binding domain-cell adhesion molecule-1 on neonatal neutrophils underlies their impaired CD18independent adhesion to endothelial cells in vitro. J Immunol 146:3372-3379

27. Abughali N, Berger M, Tosi MF 1994 Deficient total cell content of CR3 (C11b) in neonatal neutrophils. Blood 83:1086-1092

28. Jones DH, Schmalstieg FC, Dempsey K, Krater SS, Nannen DD, Smith CW, Anderson DC 1990 Subcellular distribution and mobilization of MAC-1 (CD11b/ CD18) in neonatal neutrophils. Blood 75:488-498

29. Smith CW 1993 Endothelial adhesion molecules and their role in inflammation. Can J Physiol Pharmacol 71:76-87

30. Ramsay PL, O'Brian Smith E, Hegemier S, Welty SE 1998 Early clinical markers for the development of bronchopulmonary dysplasia: soluble E-Selectin and ICAM-1. Pediatrics 102:927-932

31. Quie PG 1990 Antimicrobial defenses in the neonate. Semin Perinatol 14(4 suppl 1):2-9

32. Carr R 2000 Neutrophil production and function in newborn infants. Br J Haematol 110:18-28

33. van Eeden SF, Lawrence E, Sato Y, Kitagawa Y, Hogg JC 2000 Neutrophils released from the bone marrow by granulocyte colony-stimulating factor sequester in lung microvessels but are slow to migrate. Eur Respir J 15:1079-1086

34. Reddy RK, Xia Y, Hanikyrova M, Ross GD 1998 A mixed population of immature and mature leucocytes in umbilical cord blood results in a reduced expression and function of CR3 (CD11b/CD18). Clin Exp Immunol 114:462-467

35. Ambruso DR, Stork LC, Gibson BE, Thurman GW 1987 Increased activity of the respiratory burst in cord blood neutrophils: kinetics of the NADPH oxidase enzyme system in subcellular fractions. Pediatr Res 21:205-210

36. Gessler P, Nebe T, Birle A, Haas N, Kachel W 1996 Neutrophil respiratory burst in term and preterm neonates without signs of infection and in those with increased levels of C-reactive protein. Pediatr Res 39:843-848

37. Witko-Sarsat V, Rieu P, Descamps-Latscha B, Lesavre P, Halbwachs-Mecarelli L 2000 Neutrophils: molecules, functions and pathophysiological aspects. Lab Invest 80:617-653

38. Jobe AH, Ikegami M 1998 Mechanisms initiating lung injury in the preterm. Early Hum Dev 53:81-94

39. Chabot F, Mitchell JA, Gutteridge JM, Evans TW 1998 Reactive oxygen species in acute lung injury. Eur Respir J 11:745-757

40. Speer CP 1999 Inflammatory mechanisms in neonatal chronic lung disease. Eur J Pediatr 158(suppl 1):S18-S22

41. Welty SE 2001 Is there a role for antioxidant therapy in bronchopulmonary dysplasia? J Nutr 131:947S-950S

42. Carlton DP, Albertine KH, Cho SC, Lont M, Bland RD 1997 Role of neutrophils in lung vascular injury and edema after premature birth in lambs. J Appl Physiol 83:1307-1317

43. Speer CP 2001 New insights into the pathogenesis of pulmonary inflammation in preterm infants. Biol Neonate 79:205-209

44. Shen Z, Wu W, Hazen SL 2000 Activated leukocytes oxidatively damage DNA, RNA, and the nucleotide pool through halide-dependent formation of hydroxyl radical. Biochemistry 39:5474-5482 
45. Knaapen AM, Seiler F, Schilderman PA, Nehls P, Bruch J, Schins RP, Borm PJ 1999 Neutrophils cause oxidative DNA damage in alveolar epithelial cells. Free Radic Biol Med 27:234-240

46. Auten RL, Whorton MH, Nicholas Mason S 2002 Blocking neutrophil influx reduces DNA damage in hyperoxia-exposed newborn rat lung. Am J Respir Cell Mol Biol 26:391-397

47. Piotrowski WJ Marczak J 2000 Cellular sources of oxidants in the lung. Int J Occup Med Environ Health 13:369-385

48. Jaeschke H, Smith CW 1997 Mechanisms of neutrophil-induced parenchymal cell injury. J Leukoc Biol 61:647-653

49. Nakahara H, Sato EF, Ishisaka R, Kanno T, Yoshioka T, Yasuda T, Inoue M, Utsumi K 1998 Biochemical properties of human oral polymorphonuclear leukocytes. Free Radic Res 28:485-495

50. DeLorme MP, Yang H, Elbon-Copp C, Gao X, Barraclough-Mitchell H, Bassett DJ 2002 Hyperresponsive airways correlate with lung tissue inflammatory cell changes in ozone-exposed rats. J Toxicol Environ Health A 65:1453-1470
51. Palmer C, Roberts RL, Young PI 2004 Timing of neutrophil depletion influences long-term neuroprotection in neonatal rat hypoxic-ischemic brain injury. Pediatr Res 55:549-556

52. Luo D, Schowengerdt KO Jr, Stegner JJ, May WS Jr, Koenig JM 2003 Decreased functional caspase-3 expression in umbilical cord blood neutrophils is linked to delayed apoptosis. Pediatr Res 53:859-864

53. Woo M, Hakem R, Soengas MS, Duncan GS, Shahinian A, Kagi D, Hakem A, McCurrach M, Khoo W, Kaufman SA, Senaldi G, Howard T, Lowe SW, Mak TW 1998 Essential contribution of caspase 3/CPP32 to apoptosis and its associated nuclear changes. Genes Dev 12:806-819

54. Matsuda T, Saito H, Inoue T, Fukatsu K, Han I, Furukawa S, Ikeda S, Muto T 1998 Growth hormone inhibits apoptosis and up-regulates reactive oxygen intermediates production by human polymorphonuclear neutrophils. JPEN J Parenter Enteral Nutr 22:368-374

55. Murphy FJ, Hayes I, Cotter TG 2003 Targeting inflammatory diseases via apoptotic mechanisms. Curr Opin Pharmacol 3:412-419 